\title{
AVALIAÇÃO DA DORMÊNCIA DE Urochloa humidicola CV. LLANERO SOB DIFERENTES DOSES DE ÁCIDO GIBERÉLICO E PACLOBUTRAZOL
}

Leilanne Cristina Batista Sorigotti; Debora Maria Motta Garcia; Ceci Castilho Custódio; Fabiana Lima Abrantes

Universidade do Oeste Paulista - UNOESTE, Bacharelado em Biologia, Programa de Pós Graduação em Agronomia, Presidente Prudente, SP. E-mail: fabianaabrantes@hotmail.com

\section{RESUMO}

O objetivo foi avaliar a germinação e dormência das sementes de $U$. humidicola cv. Llanero em diferentes concentrações de ácido giberélico e paclobutrazol, utilizando sementes intactas e sementes nuas (cariopses). Utilizou-se diferentes soluções para embebição do substrato. As soluções de ácido giberélico $\left(\mathrm{GA}_{3}\right)$ foram: 0 (água pura); álcool 5\%;0,50 $\mathrm{mM} \mathrm{L}^{-1} ; 1,0 \mathrm{mM} \mathrm{L}^{-1} ; 2,0$ $\mathrm{mM} \mathrm{L}^{-1}$ e 4,0 $\mathrm{mM} \mathrm{L}^{-1}$ e de paclobutrazol (PBZ): 0; 0,05 $\mathrm{g} \mathrm{L}^{-1} ; 0,100 \mathrm{~g} \mathrm{~L}^{-1}$ e 0,200 $\mathrm{g} \mathrm{L}^{-1}$. Avaliou-se a germinação por protrusão de raiz primária, índice de velocidade de germinação e a porcentagem de dormência das sementes. Os dados foram analisados pelo teste $\mathrm{F}$ e o teste de Tukey para comparação de médias. $\mathrm{O} \mathrm{GA}_{3}$ favorece a germinação das sementes intactas, porém para a germinação do cariopse não há influência do ácido giberélico. O PBZ não inibe a germinação das sementes nuas. A germinação esta relacionada à outros fatores, além do balanço de giberelinas nas sementes.

Palavras-chave: Germinação; Giberelina; Inibidor da giberelina; Triazol; Urochloa.

\section{EVALUATION DORMANCY Urochloa humidicola CV. LLANERO UNDER DIFFERENT ACID DOSES GIBBERELLIC AND PACLOBUTRAZOL}

The objective was to evaluate the germination and dormancy of $U$. humidicola seeds cv. Llanero in different concentrations of gibberellic acid and paclobutrazol using intact seeds and naked seeds (caryopses). Different solutions are used for soaking the substrate. The solution of gibberellic acid (GA3) were: 0 (pure water) ; $5 \%$ alcohol; $0.50 \mathrm{mM} \mathrm{L}-1 ; 1.0 \mathrm{mM} \mathrm{L}-1 ; 2.0 \mathrm{mM} \mathrm{L}-1$ and $4.0 \mathrm{mM} \mathrm{L-1}$ and paclobutrazol (PBZ): 0; $0.05 \mathrm{~g} \mathrm{~L}-1 ; 0.100 \mathrm{~g} \mathrm{L-1}$ and $0.200 \mathrm{~g} \mathrm{~L}-1$. We evaluated the germination protrusion of primary root, germination speed index and the percentage of seed dormancy. Data were analyzed by $F$ test and Tukey test to compare means. The GA3 favors the germination of intact seeds, but for the germination of caryopses there is no influence of gibberellic acid. The PBZ does not inhibit the germination of naked seeds. Germination is related to other factors and the balance of gibberellins in the seeds.

Keywords: Germination, gibberellins, gibberellin inhibitor, triazole, Urochloa. 


\section{INTRODUÇÃO}

AS sementes de gramíneas forrageiras possuem alguns fatores que dificultam sua geminação (USBERT; MARTINS, 2007). O principal fator é a dormência, que pode estar associado ao armazenamento, causas fisiológicas (ALMEIDA; SILVA, 2004), ou ainda pelas barreiras que evitam entrada de oxigénio nos tegumentos (WHITEMAN; MENDRA, 1982).

Sabe-se que as giberelinas têm grande importância na germinação de sementes, pois estão envolvidas na superação da dormência e, também, na síntese de enzimas hidrolíticas envolvidas no processo de mobilização de reservas do endosperma para o embrião (TAIZ; ZEIGER, 2004).

Em contrapartida ao efeito do ácido giberélico, o composto paclobutrazol, que pertence ao grupo dos trióis é uma substância exógena que atua na inibição da biossíntese da giberelina (GA1 e GA3) (RADEMACHER, 2000), atuando no bloqueio de reações de oxidação na passagem de caureno para ácido caurenóico no caminho da síntese de substâncias giberélicas (SALISBURY, ROSS, 1992).

Bewley e Black (1994) observaram que a embebição de sementes em PBZ apresentou uma queda da atividade de enzimas que estariam ligadas no processo de germinação, pois com a presença do inibidor houve uma queda na presença de giberelinas endógenas.

A dormência em sementes de Urochloa ainda é um assunto bastante divergente, diante disto o objetivo do trabalho foi avaliar a germinação e dormência das sementes de U. humidicola cv. Llanero em diferentes concentrações de ácido giberélico e paclobutrazol utilizando sementes intactas e sementes nuas (cariopses).

\section{METODOLOGIA}

O experimento foi realizado no Laboratório de Sementes da Universidade do Oeste Paulista (UNOESTE), em Presidente Prudente, utilizando sementes puras Urochloa humidicola cv Llanero, as quais foram submetidas aos testes de germinação e tetrazólio para caracterização do lote e identificação de alta dormência e viabilidade.

O teste de germinação por protrusão de raiz foi conduzido com 4 repetições de 100 sementes, distribuídas em caixas plásticas transparente, denominadas gerbox, sobre duas folhas de papel mata borrão, umedecidos com água destilada na quantidade equivalente a 2,5 vezes a massa do papel seco, e colocadas em germinador com a temperatura alternada de 15-35드, com fotoperíodo 8 horas na maior temperatura. A contagem da germinação por protrusão de raiz foi iniciada assim que se observou a primeira protrusão de raiz com aproximadamente $2 \mathrm{~mm}$, e posteriormente a cada 2 dias computando-se as que haviam emitido raiz, até atingir 21 dias após a semeadura.

As sementes remanescentes do teste de germinação foram submetidas ao teste de tetrazólio para verificar a viabilidade das sementes não germinadas.

A viabilidade das sementes foi avaliada através do teste de tetrazólio utilizando 4 repetições de 25 sementes seguindo a metodologia proposta por (CUSTÓDIO et al., 2012). Após a coloração dos embriões foi realizada a avaliação para a identificação e contagem das sementes com as partes vitais do embrião coloridas (viáveis) (BRASIL, 2009), e os resultados expressos em porcentagem de sementes viáveis.

A dormência de sementes foi calculada pelo número de sementes não germinadas ao final do teste de germinação, submetidas ao teste de tetrazólio e consideradas viáveis, e os resultados expressos em porcentagem.

Após os testes preliminares para caracterização do lote, instalaram-se dois experimentos, um com os tratamentos com ácido giberélico e outro com paclobutrazol. Utilizando sementes intactas e sementes nuas (cariopses), sendo que para a obtenção do cariopse nu foi realizada a remoção de todas as estruturas de cobertura das sementes (glumas, lemas e páleas) com o auxílio de uma pinça histológica. 
No experimento 1 utilizou-se o delineamento inteiramente casualizado, em esquema fatorial $2 \times 5$, com quatro repetições, sendo 2 tipos de sementes: intactas e cariopse nu e cinco concentrações de ácido giberélico: 0 (água pura); 0 (álcool a 5\%); 0,50 mM L-1; 1,0 mM L-1; 2,0 mM L-1 e 4,0 mM L-1 de ácido giberélico diluído em álcool 5\%.

Além dos tratamentos com as diferentes concentrações de ácido giberélico, utilizou-se um tratamento com água pura e outro com álcool a 5\%, este último com a finalidade de mostrar que o álcool utilizado na diluição do ácido giberélico não interfere na germinação das sementes.

No experimento 2 utilizou-se o delineamento inteiramente casualizado, em esquema fatorial $2 \times 4$, com quatro repetições, sendo 2 tipos de sementes: intactas e cariopse nu e quatro concentrações de paclobutrazol: 0 (água pura), 0,05 g L-1; 0,100 g L-1 e 0,200 g L-1 de paclobutrazol diluindo em água destilada.

As sementes intactas e os cariopses foram tratados com fungicida Vitavax-Thiram 200 SC, na dose de $250 \mathrm{~mL} 100 \mathrm{~kg}$ de sementes-1, para evitar possíveis fungos durante a germinação.

Quando indicado resultado significativo pela análise de variância $(p \leq 0,05)$, as médias dos tratamentos foram comparadas pelo teste Tukey $(p \leq 0,05)$, utilizando para a análise dos dados 0 programa estatístico SISVAR (FERREIRA, 2011).

No teste de germinação por protrusão de raiz foi utilizado 4 repetições de 50 sementes intactas e 4 repetições de 50 cariopses, e conduzido conforme descrito anteriormente, utilizando as soluções citadas acima, para cada experimento. Ao final da contagem, aos 21 dias, as sementes que não germinaram, foram submetidas ao teste de tetrazólio para verificar sua viabilidade. 0 teste de tetrazólio foi realizado com todas as sementes e cariopses remanescentes, conforme metodologia descrita anteriormente.

A reposição de água foi realizada semanalmente, de acordo com a perda de água do gerbox controle. Para o controle foram colocados três gerbox com duas folhas de papel umedecidas com volume de água equivalente a 2,5 vezes a sua massa, e após a adição de água foi determinada a massa do conjunto gerbox-papel-água e uma vez por semana realizava-se a pesagem desse conjunto e a diferença média da massa inicial e final, em $\mathrm{mL}$, era considerada para reposição de água em todos os gerbox com sementes e cariopses.

Índice de velocidade de germinação por protrusão de raiz: foi realizado em conjunto com o teste de germinação, contando-se diariamente, a partir do início da germinação, o número de sementes que apresentaram protrusão de raiz, até o final do teste de germinação. $O$ cálculo do índice de velocidade de germinação foi realizado através da fórmula proposta por Maguire (1962).

\section{RESULTADOS}

Nos testes para caracterização do lote verificou-se que este apresentava $7 \%$ de germinação, $78 \%$ de viabilidade avaliada pelo teste de tetrazólio e $86 \%$ de dormência de sementes.

Experimento 1: Verificou-se interação entre o tipo de semente e a solução de embebição do papel de germinação para germinação por protrusão de raiz (GPR), índice de velocidade de germinação (IVG) e dormência de sementes (DOR) em função das diferentes concentrações de ácido giberélico (Tabela 1). 
Tabela 01. Médias de germinação por protrusão de raiz (GPR), índice de velocidade de germinação (IVG) e dormência de sementes (DOR) de Urochloa humidicola cv. Llanero, utilizando sementes nuas (cariopse) e intactas e diferentes concentrações de ácido giberélico na embebição do substrato.

\begin{tabular}{|c|c|c|c|}
\hline Tratamentos & GPR & IVG & DOR \\
\hline \multicolumn{4}{|l|}{ Sementes (A) } \\
\hline Semente nua (Cariopse) & 82 & 21 & 1 \\
\hline Semente intacta & 45 & 4 & 41 \\
\hline \multicolumn{4}{|l|}{ Concentração de ácido giberélico (B) } \\
\hline Água & 48 & 16 & 39 \\
\hline Álcool 5\% & 49 & 10 & 35 \\
\hline$A G 1,0 \mathrm{mM} \mathrm{L}^{-1}$ & 74 & 15 & 12 \\
\hline$A G 2,0 \mathrm{mM} \mathrm{L}^{-1}$ & 73 & 11 & 10 \\
\hline$A G 4,0 \mathrm{mM} \mathrm{L}^{-1}$ & 72 & 11 & 9 \\
\hline \multicolumn{4}{|c|}{ Fonte de Variação } \\
\hline Sementes (A) & $* *$ & $* *$ & $* *$ \\
\hline Concentração de ácido giberélico(B) & $* *$ & $* *$ & $* *$ \\
\hline Sementes x Concentração $(A \times B)$ & $* *$ & $* *$ & $* *$ \\
\hline
\end{tabular}

**: significativo a $1 \%$ de probabilidade pelo teste $\mathrm{F}$.

$\mathrm{Na}$ análise do desdobramento da interação para germinação (Tabela 2) observou-se que, para o cariopse, a diferença foi entre a utilização da água e ácido giberélico na concentração de 4,0 mM L-1 para embeber o papel de germinação, com maior porcentagem na presença de água pura. Já na semente intacta ocorreu maior germinação em ácido giberélico, independente da concentração utilizada. No entanto, ao analisar tipo de semente verificou-se que a germinação do cariopse foi maior do que a da semente intacta quando utilizada água, álcool ou ácido giberélico na concentração de 1,0 mM L-1, já nas demais concentrações $(2,0$ e 4,0 mM L-1) não houve diferença entre a germinação e o tipo de sementes (Tabela 2 e Figura 1). Na germinação acumulada, observa-se que a partir do nono dia após a semeadura, todas as concentrações de ácido giberélico proporcionaram germinação superior às observadas na presença de água ou de álcool, mostrando a atuação da giberelina na quebra de dormência das sementes (Figura 1).

No desdobramento da interação para o IVG observou-se que a germinação do cariopse foi mais rápida utilizando água para embeber o papel da germinação, e na semente intacta o IVG diferiu entre o ácido giberélico na concentração de 1,0 mM L-1 e a água, sendo mais rápida em ácido giberélico. Entre o tipo de semente em cada solução verificou-se que o IVG do cariopse é mais rápido independente da solução utilizada (Tabela 2).

Com relação à dormência de sementes, no cariopse não houve diferença entre as concentrações utilizadas, porém na semente intacta a dormência foi menor na presença do ácido giberélico. Entre os tipos de sementes, observou-se que a dormência do cariopse é sempre inferior à apresentada pelas sementes intactas, independente da solução para embebição do papel (Tabela 2). 
Tabela 02. Desdobramento da interação significativa semente $x$ solução de ácido giberélico na embebição do substrato para germinação por protrusão de raiz - GPR, índice de velocidade de germinação - IVG e de dormência de sementes - DOR de Urochloa humidicola cv. Llanero.

\begin{tabular}{|c|c|c|c|c|c|}
\hline \multirow[t]{2}{*}{ Sementes } & \multicolumn{5}{|c|}{ Solução } \\
\hline & Água & Álcool 5\% & $\mathrm{AG} 1 \mathrm{mM} \mathrm{L}^{-1}$ & $\mathrm{AG} 2 \mathrm{mM} \mathrm{L}^{-1}$ & AG $4 \mathrm{mM} \mathrm{L}^{-1}$ \\
\hline & \multicolumn{5}{|c|}{ Germinação de sementes - GPR (\%) } \\
\hline Semente nua (cariopse) & 89 a $A$ & 84 a $A B$ & 85 a $A B$ & 76 a $A B$ & 75 a B \\
\hline \multirow[t]{2}{*}{ Semente intacta } & $7 \mathrm{bB}$ & $14 \mathrm{~b} \mathrm{~B}$ & $62 \mathrm{~b} \mathrm{~A}$ & 70 a A & 70 a $A$ \\
\hline & \multicolumn{5}{|c|}{ Índice de velocidade de germinação - IVG } \\
\hline Semente nua (cariopse) & 32 a $A$ & 18 a BC & 23 a B & 16 a $C$ & 17 a C \\
\hline \multirow[t]{2}{*}{ Semente intacta } & $1 \mathrm{~b} \mathrm{~B}$ & $2 \mathrm{~b} \mathrm{AB}$ & $7 \mathrm{~b} \mathrm{~A}$ & $6 \mathrm{~b} \mathrm{AB}$ & $6 \mathrm{~b} \mathrm{AB}$ \\
\hline & \multicolumn{5}{|c|}{ Dormência de sementes - DOR (\%) } \\
\hline Semente nua (cariopse) & $0 \mathrm{~b} \mathrm{~A}$ & $1 \mathrm{~b} \mathrm{~A}$ & $0 \mathrm{~b} A$ & $2 \mathrm{~b} \mathrm{~A}$ & $2 \mathrm{~b} A$ \\
\hline Semente intacta & 78 a A & 69 a B & 24 a C & 17 a $C$ & 16 a $C$ \\
\hline
\end{tabular}
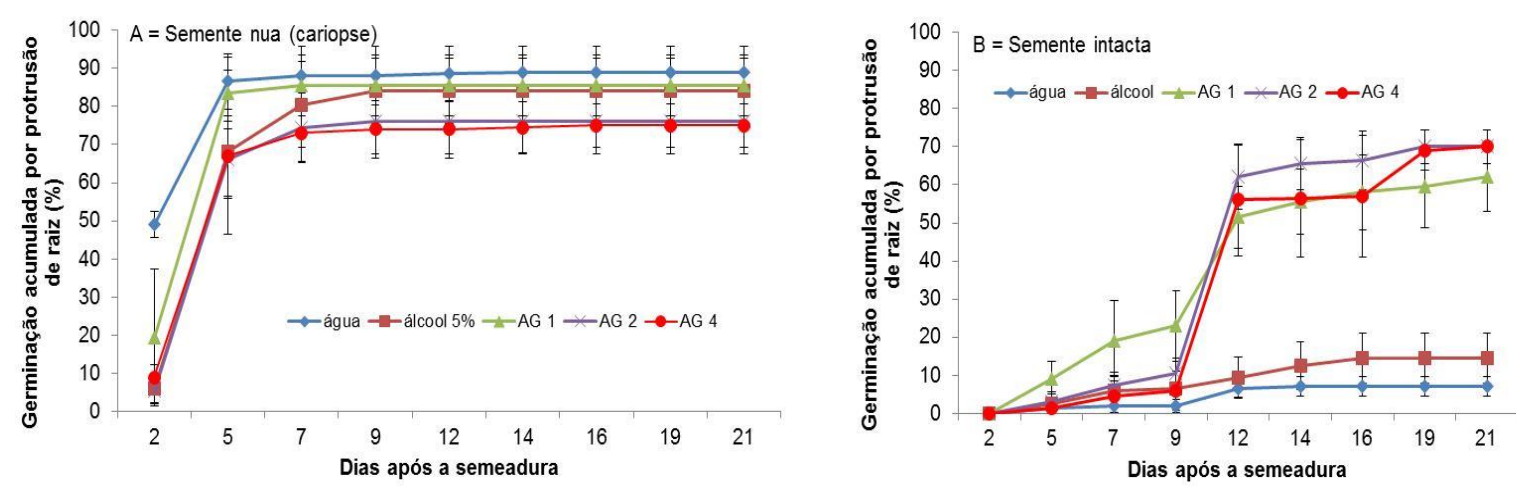

Figura 01. Germinação acumulada por protrusão de raiz (GAPR) de sementes de Urochloa humidicola cv. Llanero, submetidas a diferentes concentrações de ácido giberélico para embebição do substrato. $A G 1=1 \mathrm{mM} \mathrm{L}^{-1} ; \mathrm{AG} 2=2 \mathrm{mM} \mathrm{L}^{-1} ; \mathrm{AG} 4=4 \mathrm{mM} \mathrm{L}^{-1}$.

Experimento 2: Observa-se interação entre os tipos de sementes e a solução de embebição do substrato para germinação (GPR) e IVG, já para a dormência de sementes não houve interação, com maior dormência nas sementes intactas, enquanto que para o paclobutrazol (PBZ) não houve efeito das concentrações em relação a testemunha (água) (Tabela 3). 
Tabela 03. Médias de germinação por protrusão de raiz (GPR), índice de velocidade de germinação (IVG) e dormência de sementes (DOR) de Urochloa humidicola cv. Llanero, utilizando sementes nuas (cariopse) e sementes intactas e diferentes concentrações de paclobutrazol (PBZ) na embebição do substrato.

\begin{tabular}{lccc}
\hline Tratamentos & G & IVG & DOR \\
\hline Sementes (A) & & & \\
Semente nua (Cariopse) & 80 & 25 & $1 \mathrm{~b}$ \\
Semente intacta & 4 & 0,5 & $80 \mathrm{a}$ \\
\hline Concentração de PBZ (B) & & & \\
$0 \mathrm{~g} \mathrm{~L}^{-1}$ (água) & 48 & 16 & 39 \\
$0,05 \mathrm{~g} \mathrm{~L}^{-1}$ & 38 & 11 & 41 \\
$0,1 \mathrm{~g} \mathrm{~L}^{-1}$ & 42 & 11 & 42 \\
$0,2 \mathrm{~g} \mathrm{~L}^{-1}$ & 40 & 12 & 40 \\
\hline & & & \\
\hline Sementes (A) & $* *$ & $* *$ & $\mathrm{~ns}$ \\
Concentração (B) & $* *$ & $* *$ & $\mathrm{~ns}$ \\
Concentração x Solução (A x B) & & $* *$ & $* *$ \\
\hline
\end{tabular}

Médias seguidas de letras minúsculas distintas, na coluna diferem estatisticamente entre si, pelo teste de Tukey a 5\% de probabilidade. ${ }^{* *}$ e ns são: significativo a $1 \%$ de probabilidade e não significativo pelo teste $\mathrm{F}$.

Para a semente nua (cariopse) na concentração zero e 0,1 g L-1 PBZ observou-se maior taxa de germinação, mostrando que o PBZ não inibiu a germinação. Já nas sementes intactas, a germinação foi baixa e não foi notada diferença significativa entre as concentrações. Houve grande diferença de GPR entre a semente intacta e a semente nua, independente da solução de embebição (Tabela 4 e Figura 2), demonstrando que a remoção dos envoltórios tem maior influência na superação da dormência, pois após a remoção as doses de PBZ não inibiram a germinação, levando a hipótese de que a concentração usada não inibiu a síntese de giberelina e consequentemente a germinação, ou que uma vez removida às estruturas das sementes a giberlina já foi sintetizada e o PBZ não exerce efeito na giberelina sintetizada.

Mensurando o IVG, notou se que a germinação foi mais rápida ao utilizar a água como solução de embebição para as sementes nuas, e para as intactas não houve diferença significativa entre as concentrações, porém entre os tipos de sementes verificou-se que independente da concentração de PBZ a velocidade de germinação foi maior nas sementes nuas (Tabela 4).

Tabela 04. Desdobramento da interação significativa semente x solução de paclobutrazol (PBZ) na embebição do substrato para germinação por protrusão de raiz (GPR) de Urochloa humidicola cv. Llanero.

\begin{tabular}{lcccc}
\hline Sementes & \multicolumn{4}{c}{ Concentração de paclobutrazol (g L ${ }^{-1}$ ) } \\
\cline { 2 - 5 } & 0 & 0,05 & 0,1 & 0,2 \\
\hline \multirow{2}{*}{ Semente nua (cariopse) } & \multicolumn{4}{c}{ Germinação por protrusão de raiz - GPR (\%) } \\
Semente intacta & 89 a A & 71 a C & 83 a AB & 76 a BC \\
\hline & 7 b A & 4 b A & 1 b A & 4 b A \\
Semente nua (cariopse) & \multicolumn{4}{c}{ Índice de velocidade de germinação - IVG } \\
Semente intacta & 32,3 a A & 22,5 a B & 22,6 a B & 23,0 a B \\
\hline
\end{tabular}

Médias seguidas de letras minúsculas distintas, na coluna, e maiúscula na linha, diferem estatisticamente entre si, pelo teste de Tukey a $5 \%$ de probabilidade. 

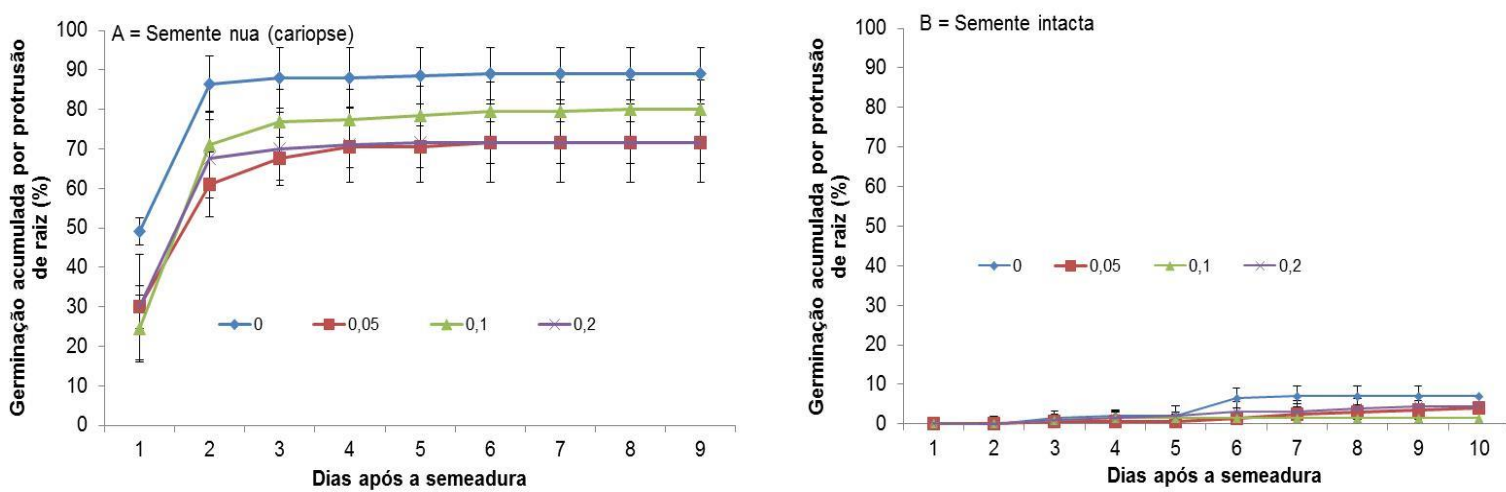

Figura 02. Germinação acumulada por protrusão de raiz (GAPR) de sementes de Urochloa humidicola cv. Llanero, submetidas a diferentes concentrações de paclobutrazol para embebição do substrato.

\section{DISCUSSÃO}

Silva (2013), trabalhando com Braquiaria, observou resultados positivos na germinação com a utilização do ácido giberélico. Assim como Vieira et al. (1998) que constaram que para sementes de braquiarão cv. Marandu, a quebra da dormência foi mais significativa quando utilizou acido giberélico. Discordando de Lacerda et al. (2010) que observaram que a imersão em água fervente foi mais eficientes para superar a dormência de Urochloa brizantha cv. Marandu do que o ácido giberélico e ácido sulfúrico. A giberelina tem grande influência na germinação, pois a produção e/ou secreção de várias enzimas hidrolíticas, envolvidas na solubilização das reservas do endosperma são promovidas pela giberelina, quando o embrião a sintetiza e a libera no endosperma durante a germinação, com isso o embrião dos cereais mobiliza suas próprias reservas que estimulam a função digestiva da camada de aleurona (TAIZ; ZEIGER, 2004).

Segundo Graebe (1987) o paclobutrazol atua na inibição da biossíntese de giberelina, pois esse composto bloqueia a oxidação do caureno. A enzima responsável por esse processo é a caureno oxidase, que é inibida pela presença dos triazóis, porém nessa pesquisa essa inibição só foi observada em sementes intactas, mostrando que germinação das sementes de Urochloa humidicola cv. Llanero tem maior relação com a presença dos envoltórios do que com a atuação da giberelina. Uma vez removidos os envoltórios não é necessário o acréscimo de giberelina exógena.

A germinação e velocidade de germinação das sementes intactas, com a presença do ácido giberélico se sobressaem em comparação com o paclobutrazol, concordando com resultados obtidos por Melo (2014) quando tratou sementes de tomates e observou redução na germinação utilizando solução de paclobutrazol.

As sementes nuas possuem maior germinação e maior velocidade de germinação quando comparadas com sementes intactas, independente da solução e concentrações utilizadas. Esse aumento na taxa de germinação de sementes nuas pode estar ligado às restrições impostas pela cobertura da semente à entrada de oxigênio (WHITEMAN; MEDRA, 1982). As sementes intactas não alcançaram superação total da dormência com giberelina, assim como os cariopses não tiveram a germinação inibida pelo PBZ corroborando com a hipótese de Van Staden (1983), de que a dormência em sementes não é controlada apenas pela síntese de giberelinas, mas sim por um equilíbrio hormonal de promotores e inibidores.

\section{CONCLUSÃO}

O ácido giberélico favorece a germinação das sementes intactas, porém para a germinação do cariopse não há influência do ácido giberélico. O paclobutrazol não inibe a germinação das sementes nuas (cariopses). A germinação esta relacionada à outros fatores, além do balanço de giberelinas nas sementes. 


\section{REFERÊNCIAS}

ALMEIDA, C.R.; SILVA, W.R. Comportamento da dormência em sementes de Brachiaria dictyoneura cv. Llanero submetidas às ações do calor e do ácido sulfúrico. Revista Brasileira de Sementes, v.26, n.1, 2004. http://dx.doi.org/10.1590/S0101-31222004000100007

BEWLEY, J.D.; BLACK, M. Seeds: physiology of development and germination. New York: Plenum, 1994. 445p. https://doi.org/10.1007/978-1-4899-1002-8

BRASIL, Ministério da Agricultura Pecuária e Abastecimento. Regras para análise de Sementes. Brasília: SNDA/DNDV/CLV, 2009. 399p.

CUSTÓDIO, C.C; DAMASCENO, R.L.; MACHADO NETO, N.B. Imagens digitalizadas na interpretação do teste de tetrazólio em sementes de Brachiaria brizantha. Revista Brasileira de Sementes, v.34, n.2, p.334-341, 2012. http://dx.doi.org/10.1590/S0101-31222012000200020

FERREIRA, D. F. Sisvar: um sistema computacional de análise estatística. Ciência e Agrotecnologia, v.35, n.6, p.1039-1042, 2011. http://dx.doi.org/10.1590/S1413-70542011000600001

GRAEBE, J.E. Gibberellin biosynthesis and control. Annual Review of Plant Physiology, v.38, p.419465, 1987. http://dx.doi.org/10.1146/annurev.pp.38.060187.002223

LACERDA, M.J.R.; CABRAL, J.S.R.; SALES, J.F.; FREITAS, K.R.; FONTES, A.J. Superação da dormência de sementes de Brachiaria brizantha cv. "Marandu". Semina: Ciências Agrárias, v. 31, n. 4, p. 823828, 2010. https://doi.org/10.5433/1679-0359.2010v31n4p823

MAGUIRE, J. D. Speeds of germination-aid selection and evaluation or seedling emergence and $\begin{array}{llrrr}\text { vigor. Crop } & \text { Science, } & \text { v.2, } & \text { p.176-177, } & 1962 .\end{array}$ https://doi.org/10.2135/cropsci1962.0011183X000200020033x

MELO, A. P.C.; SELEGUINI,A.;VELOSO, V. R. S. Peliculização de sementes de tomate associada ao paclobutrazol. Bragantia, v.73, n.2, p.123-129, 2014. https://doi.org/10.1590/brag.2014.026

RADEMACHER, W. Growth retardants: effects on gibberellin biosynthesis and other metabolic pathways. Annual Review of Plant Physiology and Plant Molecular Biology, v.51, p.501-531, 2000. https://doi.org/10.1146/annurev.arplant.51.1.501

SALISBURY, F.B.; ROSS, C.W. Plant Physiology. Belmont, Wadsworth, 1992. 682p.

SILVA. A.B; LANDGRAF.P.R.C; MACHADO. G.W.O. Germinação de sementes de braquiária sob diferentes concentrações de giberelina. Semina: Ciências Agrárias, v.34, n.2, p. 657-662, 2013. https://doi.org/10.5433/1679-0359.2013v34n2p657

TAIZ, L; ZEIGER, E. Fisiologia vegetal. 3 ed. Porto Alegre: Artmed, 2004. 719p.

USBERTI, R.; MARTINS, L. Sulphuric acid scarification effects on Brachiaria brizantha, B. humidicola and Panicum maximum seed dormancy release. Revista Brasileira de Sementes, v.29, n.2, p.143147, 2007. http://dx.doi.org/10.1590/S0101-31222007000200020

VAN STADEN, J. Seeds and cytokinins. Physiologia Plantarum, v.58, p.340-346,1983. http://dx.doi.org/10.1111/j.1399-3054.1983.tb04190.x 
VIEIRA, H.D.; SILVA, R.F.; BARROS, R.S. Efeito de substâncias reguladoras de crescimento sobre a germinação de sementes de braquiarão cv. Mandaru. Revista Brasileira de Fisiologia Vegetal, v.10, n.2, p.143-148, 1998. Disponível em: http://www.cnpdia.embrapa.br/rbfv/pdfs/v10n2p143.pdf

WHITEMAN, P.C; MENDRA, K. Effects of storage and seed treatments on germination of Brachiaria decumbens. Seed Science and Technology, v.12, n.1, p.233-242, 1982. 